\title{
Review:
}

\section{Research progress of the role and mechanism of extracellular signal- regulated protein kinase 5 (ERK5) pathway in pathological pain*}

\author{
Li-na $\mathrm{YU}^{\S 1}$, Li-hong $\mathrm{SUN}^{\S 2}$, Min WANG ${ }^{2}$, Min YAN $\$ 1,2$ \\ ( ${ }^{1}$ Department of Anesthesiology, the Second Affiliated Hospital, School of Medicine, Zhejiang University, Hangzhou 310009, China) \\ ( ${ }^{2}$ Jiangsu Province Key Laboratory of Anesthesiology, Jiangsu Province Key Laboratory of Anesthesia and \\ Analgesia Application Technology, Xuzhou Medical University, Xuzhou 221000, China) \\ †E-mail: zryanmin@zju.edu.cn
}

Received Apr. 29, 2016; Revision accepted July 13, 2016; Crosschecked Sept. 11, 2016

\begin{abstract}
Extracellular signal-regulated protein kinase 5 (ERK5), also known as big mitogen-activated protein kinase 1 (MAPK1), is an important member of ERK family, which is a subfamily of the large MAPK family. ERK5 is expressed in many tissues, including the dorsal root ganglion (DRG) neurons and the spinal cord. In this review, we focus on elaborating ERK5-associated pathway in pathological pain, in which the ERK5/CREB (cyclic adenosine monophosphate (CAMP)-response element-binding protein) pathway plays a crucial role in the transduction of pain signal and contributes to pain hypersensitivity. ERK5 activation in the spinal dorsal horn occurs mainly in microglia. The activation of ERK5 can be mediated by $\mathrm{N}$-methyl-D-aspartate (NMDA) receptors. We also elaborate the relationship between ERK5 activation and nerve growth factor-tyrosine kinase A (NGF-TrkA), and the connection between ERK5 activation and brain-derived neurotrophic factor (BDNF) in pathological pain in detail.
\end{abstract}

Key words: Extracellular signal-regulated protein kinase 5 (ERK5), Pain, Cyclic adenosine monophosphate (cAMP)response element-binding protein (CREB), $N$-methyl-D-aspartate (NMDA), Nerve growth factor (NGF), Brain-derived neurotrophic factor (BDNF)

http://dx.doi.org/10.1631/jzus.B1600188

CLC number: R614

\section{Introduction}

The mitogen-activated protein kinase (MAPK) cascade is a superfamily of intracellular signal transduction molecules, which includes extracellular signal-regulated protein kinase 1/2 (ERK1/2), p38 MAPK, c-jun $N$-terminal kinase (JNK), and ERK5 (Widmann et al., 1999; Kyriakis and Avruch, 2001). MAPKs transduce a broad range of extracellular stimuli into intracellular responses and can regulate diverse physiological and pathological processes (Widmann et al., 1999; Sweatt, 2001). Pathological

\footnotetext{
‡ Corresponding author

$\S$ The two authors contributed equally to this work

* Project supported by the Medical and Healthcare Project of Zhejiang Province (No. 2015119381), China

(iD) ORCID: Li-hong SUN, http://orcid.org/0000-0003-1726-059X

(C) Zhejiang University and Springer-Verlag Berlin Heidelberg 2016
}

pain is an expression of neuronal plasticity and is characterized by pain hypersensitivity. There are two important forms of pathological pain: inflammatory pain, which is initiated by tissue damage or inflammation, and neuropathic pain, which results from nerve injuries ( $\mathrm{Ji}$ and Woolf, 2001). There are compelling reports indicating that the activation of MAPK in primary afferents and the spinal cord contributes to pain hypersensitivity and neuronal plasticity in pathological pain (Chang and Karin, 2001; Ji and Strichartz, 2004; Obata and Noguchi, 2004; Katsura et al., 2007).

The ERK family participates in regulating nociceptive activities in primary sensory neurons after various kinds of pathologic stimuli, including peripheral nerve injuries and inflammation ( $\mathrm{Ji}$ et al., 1999). In contrast to ERK $1 / 2$ whose role has been studied extensively in the past (Rudolph et al., 2015), it is not until recent years that researchers have paid 
attention to the role of ERK5 pathway in regulating pain signals and have made great progress (Imbe et al., 2011). ERK5 is specifically phosphorylated and activated by MAPK kinase 5 (MEK5). Several studies have reported that activation of ERK5 can regulate neuronal activity and thus modulate neuroplasticity, which is defined as the capacity of neurons to change their function, chemical profile, and structure (Ji and Woolf, 2001; Cao et al., 2013). There are many reports indicating that ERK5 activation in the dorsal root ganglion (DRG) and the spinal cord takes part in mediating the transduction of pain signals, and contributes to hyperalgesia and allodynia after peripheral inflammation or nerve injuries (Mizushima et al., 2007; Obata et al., 2007; Xiao et al., 2008). Given the crucial role of ERK5 in pain signal transduction, this review aims at summarizing the role of ERK5 pathway in pathological pain.

\section{ERK5 pathway is involved in inflammatory pain and neuropathic pain}

Inflammation induced by complete Freund's adjuvant (CFA) in rats could produce heat and cold hyperalgesia and induce the activation of ERK5 in DRG neurons and the spinal cord (Obata et al., 2007; Xiao et al., 2008). In the CFA-induced inflammatory pain model, the level of total ERK5 expression remained unaltered, but the level of phosphorylated ERK5 (p-ERK5; the activated state of ERK5 via phosphorylation) increased substantially. ERK5 activation caused by persistent peripheral inflammation was mainly in ipsilateral DRG and laminae I-II neurons of the superficial dorsal horn (Snider and McMahon, 1998). Katsura et al. (2007) found that in the acute inflammatory pain model induced by capsaicin injection in rats, there also occurred an acute increase in the level of p-ERK5. Besides, Mizushima et al. (2007) demonstrated that noxious heat and cold stimuli could lead to the activation of ERK5 in an intensity-dependent manner. Antisense knockdown of ERK5 could suppress the hyperalgesia caused by peripheral inflammation (Katsura et al., 2007; Xiao et al., 2008). Furthermore, the peripheral inflammationinduced c-fos expression in the DRG and the spinal cord could be significantly reduced by antisense knockdown of ERK5 (Xiao et al., 2008). It is worth mentioning that $\mathrm{c}$-fos protein is the product of the c-fos immediate early gene (IEG), and has been characterized as an indicator of neuronal activation in the central nervous system (CNS) (Coggeshall, 2005).

Neuropathic pain, which occurs after nerve injuries, produces chronic pain states characterized by hyperalgesia, allodynia, and spontaneous pain. It is known that neuropathic pain is a result of injuryinduced peripheral and central neural plasticity (Woolf and Salter, 2000; Ji and Strichartz, 2004). Nerve injuries can induce the activation of ERK 5 both in primary afferent neurons and the spinal cord in a neuropathic pain model induced by chronic constriction injury (CCI) or spared nerve injury (SNI) (Sun et al., 2013). After partial nerve injuries, ERK5 activation regulates the expression of the transient receptor potential V1 (TRPV1) and the transient receptor potential A1 (TRPA1). Knockdown of ERK5 decreases the induction of TRPV1 and TRPA1 and inhibits the heat and cold hypersensitivity induced by SNI (Obata et al., 2007). In brief, activation of ERK5 contributes to pain hypersensitivity, while antisense knockdown of ERK5, where the effects are present both in DRG and the spinal cord, can suppress the nerve injury-induced mechanical allodynia and thermal hyperalgesia (Jeong et al., 2014). Taken together, these findings suggest that the activation of ERK5 in primary sensory neurons and the spinal cord plays a crucial role in the pathogenesis of inflammatory pain and neuropathic pain.

\section{ERK5/CREB pathway contributes to hy- persensitivity in pathological pain}

As an intracellular signal transduction molecule, activated ERK5 translocates to the nucleus, phosphorylates several nuclear factors, and adjusts the gene expression directly or indirectly (Cavanaugh, 2004). Many molecules are found to be downstream targets of the ERK5 pathway, including myocyte enhancer factor 2C (MEF2C), myocyte enhancer factor 2A (MEF2A), synapse-associated protein 1a (Sap1a), and cyclic adenosine monophosphate (cAMP)response element-binding protein (CREB) (Kato et al., 1997; Yang et al., 1998; Kamakura et al., 1999). Here we describe the ERK5/CREB pathway, which plays an important role in pain signal transduction. 
After peripheral inflammation, p-ERK5 translocates to the nucleus and activates the transcription factor CREB through the activation of $\mathrm{p} 90$ ribosomal S6 kinase (RSK). The phosphorylated CREB (pCREB; the activated state of CREB via phosphorylation) then binds to the cAMP-response element (CRE) in the promoter regions of the DNA and initiates the transcription of genes (Watson et al., 2001). The CREB-binding site CRE has been identified in the promoter regions of some "pain genes," including c-fos, zif 268, cyclooxygenase-2 (COX-2), neurokinin-1 (NK-1), dynorphin, calcitonin gene-related peptide (CGRP), and brain-derived neurotrophic factor (BDNF) (Wisden et al., 1990; Mannion et al., 1999). Furthermore, the expression of CREBdependent gene has been suggested to contribute to the central sensitization associated with persistent pain states (Liu et al., 2003). Thus, it is reasonable to draw the conclusion that the activation of ERK5/ CREB pathway in DRG and the spinal cord contributes to, at least partially, pain hypersensitivity and allodynia after peripheral inflammation.

Similarly, after nerve injuries, p-CREB level in the spinal cord also increases, the time course level of which is matched with the level of p-ERK5 and the degree of behavioral hyperalgesia. Antisense knockdown of ERK5 markedly inhibits the increase of p-CREB expression after nerve injuries (Zhang et al., 2009). This indicates that CREB acts as one of the downstream targets of the ERK5 pathway in neuropathic pain. ERK5 takes part in regulating pain-related gene transcription via CREB phosphorylation and contributes to the nerve injury-induced long-term pain hypersensitivity (Ji and Woolf, 2001). Thus, the ERK5/CREB pathway also plays a substantial role in the pathogenesis of neuropathic pain. In conclusion, these studies demonstrate that the ERK5/CREB pathway contributes to hypersensitivity both in inflammatory and neuropathic pain (Fig. 1).

\section{ERK5 activation in the spinal dorsal horn occurs mainly in microglia}

ERK5 activation in the spinal dorsal horn takes place mainly in microglia, rather than in neurons or astrocytes (Obata et al., 2007). Microglia is a kind of glial cells in the CNS, and it is well known that the

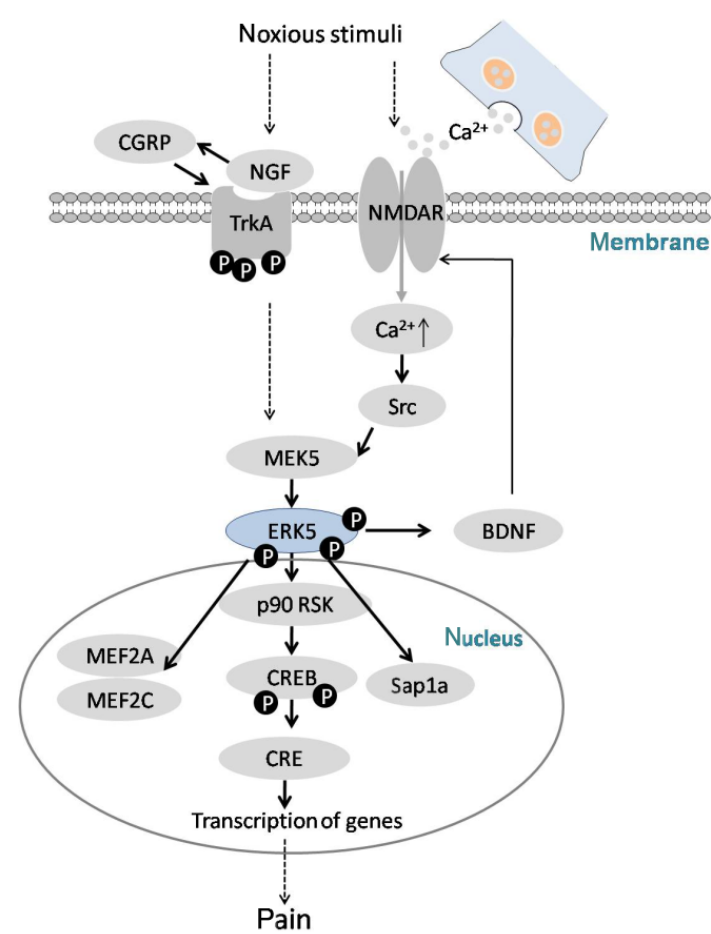

Fig. 1 Upstream and downstream mechanisms of the ERK5 signaling cascade in DRG neurons

Dashed lines indicate the need for further examination of possible signaling or the mechanism, which is complicated and abbreviated in this text. See text for details

activation of microglia occurs after peripheral nerve injuries and contributes to the development of neuronal hyperalgesia and allodynia which underlies persistent pain conditions (Obata et al., 2007). Microglia maintains a strong relationship with neurons and can change the activity of those neurons. The interaction between microglia and neurons plays important roles in the development of central sensitization (Ren and Dubner, 2016). Central sensitization is an activity-dependent functional plasticity, one pivotal feature of which is the increased excitability of nociceptive neurons in the spinal cord ( $\mathrm{Ji}$ and Woolf, 2001). The specific mechanisms of nociceptive signal transduction between microglia and neurons are still not well established. Some studies have confirmed that the chemokine CX3CL1 and its receptor CX3CR1 play an important role in the interaction between microglia and neurons (Gao and $\mathrm{Ji}$, 2010). In a recent study performed by our team, we demonstrated that CX3CR1 is required for ERK5 activation in the microglia after nerve injuries. The activation of ERK 5 in the spinal cord could contribute to pain hypersensitivity induced by CX3CL1. CX3CL1/ 
CX3CR1 could mediate the nociceptive signaling between microglia and neurons through ERK5mediated microglia activation (Sun et al., 2013). In addition, activated microglia in the spinal cord contributes to the initiation of pathological pain responses and the development of neural plasticity after nerve injuries or peripheral inflammation via accelerating the production of proinflammatory cytokines, including interleukin-1 $\beta$ (IL-1 $\beta$ ), IL-6, and tumor necrosis factor- $\alpha$ (TNF- $\alpha)$ (DeLeo and Yezierski, 2001; Watkins and Maier, 2003). Proinflammatory cytokines are known to induce behavioral hypersensitivity and play a crucial role in the maintenance of chronic pain states (Raghavendra et al., 2003). Activation of some cellular events such as MAPK in the microglia could enhance the release of those proinflammatory mediators (Raghavendra et al., 2003). Thus, it can be reasonably inferred that microglia and the activation of ERK5 in microglia in the spinal cord may be attractive targets for blocking neuronal nociceptive signal transmission (Sweitzer et al., 2001).

\section{ERK5 activation can be mediated by $\mathrm{N}$-methyl-D-aspartate receptor}

The activation of ERK 5 can be mediated by the $\mathrm{N}$-methyl-D-aspartate (NMDA) receptor and the subsequent associated intracellular signal transduction cascades (Wang et al., 2004). NMDA receptor is a kind of ionotropic glutamate receptors, and one important role of the activated NMDA receptor is mediating calcium influx. NMDA receptor activation can trigger an increase of intracellular $\mathrm{Ca}^{2+}$ concentration and activate the ERK5 signal pathway. The activated ERK5 transmits the glutamate signals to the nucleus by phosphorylating nuclear transcription factors, and thus contributes to the development and maintenance of chronic pain (Zhang et al., 2009). The calcium influx caused by NMDA receptor activation can induce Src kinase activation, which is an important activator of ERK5 (Wang et al., 2004) (Fig. 1). In brief, NMDA receptors play important roles in the activation of ERK 5 during the pathological process of chronic pain. Likewise, NMDA receptor and the activation of ERK5 mediated by NMDA receptor may also be potential targets for blocking nociceptive signal transmission.

\section{Nerve growth factor has been implicated in the process of ERK5 activation}

Nerve growth factor (NGF) is a member of the neurotrophin family and is involved in the regulation of the growth, maintenance, proliferation, and survival of certain target neurons. NGF is suggested to be an important mediator in the production of inflammatory pain (Lewin and Mendell, 1993; Sah et al., 2003; Hefti et al., 2006). NGF can be released from keratinocytes, fibroblasts, Schwann cells, and mast cells in the tissues after injury or inflammation $(\mathrm{Wu}$ et al., 2007; Radtke et al., 2010). The interaction between NGF and its receptor tyrosine kinase A (TrkA) has been implicated in the process of ERK5 activation (Watson et al., 2001; Wang and Tournier, 2006). The CFA injection-induced ERK5 phosphorylation takes place mainly at the high-affinity receptor for NGFTrkA containing neurons, and the activation of ERK5 plays a key role in NGF-induced sensory neuronal survival response (Watson et al., 2001).

In DRG neurons, about half of the primary sensory neurons are peptidergic neurons marked by the calcitonin gene related peptide (CGRP) (Ju et al., 1987; McCarthy and Lawson, 1990). CGRP is one of the most important nociceptive markers in inflammatory pain (Benemei et al., 2009; Han et al., 2010). Mice lacking CGRP or whose CGRP activity was inhibited pharmacologically do not develop hyperalgesia after inflammation (Smith et al., 1992; Springer et al., 2003). The CGRP-expressing neurons can present the active form of TrkA and then the activated TrkA is able to respond to NGF. Many studies have suggested that there is a close relationship between NGF and CGRP in sensory neurons (Schicho and Donnerer, 1999; Shadiack et al., 2001; Yu et al., 2012). Injection of NGF antiserum can decrease the levels of CGRP protein in the DRG of non-operative animals (Shadiack et al., 2001). The level of CGRP mRNA in DRG is also absent in TrkA ${ }^{-/-}$mice (Patel et al., 2000). These studies all support the close interplay between NGF-TrkA and CGRP. In the CGRP promoter, there is a cAMP-responsive element that is responsive to CREB (Lanigan and Russo, 1997; Freeland et al., 2000). So, it is easy to understand why NGF can also regulate CREB activation in sensory neurons (Lonze and Ginty, 2002). NGF is released after the stimulation of nerve terminals and can 
influence the neuronal function through binding to TrkA (Riccio et al., 1997; Watson et al., 1999; Campenot and MacInnis, 2004). While NGF binds to TrkA in neurons, several pathways are activated simultaneously, including the ERK5/CREB pathway, which leads to the enhancement of targeted gene expression (Perkinton et al., 2002; Segal, 2003). It has been reported that NGF regulates CREB activation in sensory neurons and contributes to neuronal plasticity. This further verifies NGF's contribution to the ERK5/ CREB pathway in pain signal transduction (Lonze and Ginty, 2002) (Fig. 1).

Meanwhile, in sensory neurons, ERK5 activation is essential in mediating the neurons' survival response to NGF (Watson et al., 2001). NGF activates CGRP and CREB in primary sensory neurons in the DRG and regulates the activity of sensory neurons. This process can be mediated by the activation of ERK5 (Yu et al., 2012). Inhibition of ERK5 activity could block the ability of NGF to increase CGRP expression in cultured DRG neurons (Park et al., 2010).

Besides, it has also been reported that after CFA injection-induced inflammation, NGF is synthesized and released in the inflamed tissue, which leads to the increased expression of TRPV1 and TRPA1 through ERK5 activation (Obata et al., 2007). Many studies have shown that TRPV1 and TRPA1 are respectively required for peripheral sensitization to noxious heat and cold stimuli (Caterina et al., 2000). Therefore, the activation of ERK5 pathway is also essential to NGFinduced increase in the expression of TRP channels, and thus contributes to heat and cold hyperalgesia after peripheral inflammation.

Taken together, all these studies support the conclusion that, during inflammatory pain, NGF regulates sensory activity and influences the neuronal function via regulating CGRP expression, and plays an important role in the ERK5/CREB signal transduction process.

\section{ERK5 activation regulates the expression of BDNF}

In neuropathic pain, ERK5 activation can regulate the expression of BDNF, which is a crucial signaling molecule between microglia and neurons
(Coull et al., 2005; Katsura et al., 2007). BDNF is a member of the neurotrophin family, which has been shown to play important roles in the development of pathologic pain (Sah et al., 2003; Pezet and McMahon, 2006). In injured DRG neurons, especially in medium- and large-sized neurons, BDNFs are dramatically increased, the process of which can be regulated by ERK5 activation (Obata et al., 2007). After nerve injuries, the BDNFs in primary afferents are transported to the central terminals in the spinal dorsal horn, where they regulate the excitability of the spinal neurons and play roles in neuropathic sensations (Michael et al., 1997). It has been identified that the release of BDNF can be mediated by NGF via extracellular signal-regulated kinases (ERKs) (Matsuoka and Yang, 2012). In DRG neurons expressing TrkA, systemic application of NGF to rats results in an upregulation of the BDNF level, which plays a crucial role in mediating pathological pain signal transmission (Apfel et al., 1996). Meanwhile, BDNF can enhance the excitability of the neurons in spinal dorsal horn through several mechanisms, including activation of certain NMDA receptors (Geng et al., 2010). Thus, ERK5 activation regulates the expression of BDNFs and the BDNFs can modulate the neuron hyperexcitability during chronic neuropathic pain (Fig. 1).

\section{Conclusions and perspectives}

The study of molecular mechanisms in nociceptive signal transmission has always been popular in the field chronic pain research. In this review, we summarized the ERK5 pathway and described the role of ERK5 in pain signal transduction in pathological pain. Noxious stimuli can induce ERK5 activation in the DRG neurons and the spinal cord. The activation of the ERK5 pathway contributes to pain hypersensitivity and is involved in the formation of central sensitization in pathological pain. In supraspinal structures such as the descending pain modulation system, some MAPKs, including ERK1/2, p38, and JNK, take part in mediating neuropathic pain (Imbe et al., 2011). At the level of the molecular structure, the amino-terminal half of ERK 5 contains the kinase domain, which is similar to that of ERK1/2. Besides, PD98059 and U0126, which are inhibitors of 
MEK1/2-ERK1/2, can also inhibit the activation of ERK5 (Mizushima et al., 2007). It is possible that ERK5 and ERK1/2 regulate some homologous cellular signal transduction. Meanwhile, several studies have reported that the ERK5 pathway can modulate many pathological processes in the supraspinal structure. Qi et al. (2009) found that following psychophysical stress, the activity of ERK5 changes in the frontal cortex. In a recent research, Wang et al. (2015) have confirmed that the activation of ERK5 in the cerebrospinal fluid-contacting nucleus (CSF-CN) contributes to the development of neuropathic pain. Therefore, it is very likely that ERK5 activation may also be involved in the descending pain modulation system. More studies are needed to examine the role of the ERK5 pathway in the supraspinal structures in modulating neuropathic pain.

Better and deeper investigation of the ERK5 transduction pathway may provide further insights into the potential mechanisms underlying pathological pain and will help us exploit new therapeutic opportunities targeted specifically at inhibiting the pain signal transduction.

\section{Acknowledgements}

We sincerely thank Dr. Qing-he ZHOU (School of Medicine, Zhejiang University, China) for his guidance.

\section{Compliance with ethics guidelines}

Li-na YU, Li-hong SUN, Min WANG, and Min YAN declare that they have no conflict of interest.

This article does not contain any studies with human or animal subjects performed by any of the authors.

\section{References}

Apfel, S.C., Wright, D.E., Wiideman, A.M., et al., 1996. Nerve growth factor regulates the expression of brain-derived neurotrophic factor mRNA in the peripheral nervous system. Mol. Cell. Neurosci., 7(2):134-142. http://dx.doi.org/10.1006/mcne.1996.0010

Benemei, S., Nicoletti, P., Capone, J.G., et al., 2009. CGRP receptors in the control of pain and inflammation. Curr. Opin. Pharmacol., 9(1):9-14.

http://dx.doi.org/10.1016/j.coph.2008.12.007

Campenot, R.B., MacInnis, B.L., 2004. Retrograde transport of neurotrophins: fact and function. J. Neurobiol., 58(2): 217-229. http://dx.doi.org/10.1002/neu.10322

Cao, Y., Li, K., Fu, K.Y., et al., 2013. Central sensitization and MAPKs are involved in occlusal interference-induced facial pain in rats. J. Pain, 14(8):793-807. http://dx.doi.org/10.1016/j.jpain.2013.02.005

Caterina, M.J., Leffler, A., Malmberg, A.B., et al., 2000. Impaired nociception and pain sensation in mice lacking the capsaicin receptor. Science, 288(5464):306-313. $\mathrm{http} / / / \mathrm{dx}$.doi.org/10.1126/science.288.5464.306

Cavanaugh, J.E., 2004. Role of extracellular signal regulated kinase 5 in neuronal survival. Eur. J. Biochem., 271(11): 2056-2059. http://dx.doi.org/10.1111/j.1432-1033.2004.04131.x

Chang, L., Karin, M., 2001. Mammalian MAP kinase signalling cascades. Nature, 410(6824):37-40. http://dx.doi.org/10.1038/35065000

Coggeshall, R.E., 2005. Fos, nociception and the dorsal horn. Prog. Neurobiol., 77(5):299-352.

Coull, J.A., Beggs, S., Boudreau, D., et al., 2005. BDNF from microglia causes the shift in neuronal anion gradient underlying neuropathic pain. Nature, 438(7070):1017-1021. http://dx.doi.org/10.1038/nature04223

DeLeo, J.A., Yezierski, R.P., 2001. The role of neuroinflammation and neuroimmune activation in persistent pain. Pain, 90(1-2):1-6. http://dx.doi.org/10.1016/S0304-3959(00)00490-5

Freeland, K., Liu, Y.Z., Latchman, D.S., 2000. Distinct signalling pathways mediate the cAMP response element (CRE)-dependent activation of the calcitonin gene-related peptide gene promoter by cAMP and nerve growth factor. Biochem. J., 345(2):233-238. http://dx.doi.org/10.1042/bj3450233

Gao, Y.J., Ji, R.R., 2010. Chemokines, neuronal-glial interactions, and central processing of neuropathic pain. Pharmacol. Ther., 126(1):56-68. http://dx.doi.org/10.1016/j.pharmthera.2010.01.002

Geng, S.J., Liao, F.F., Dang, W.H., et al., 2010. Contribution of the spinal cord BDNF to the development of neuropathic pain by activation of the NR2B-containing NMDA receptors in rats with spinal nerve ligation. Exp. Neurol., 222(2):256-266. http://dx.doi.org/10.1016/j.expneurol.2010.01.003

Han, J.S., Adwanikar, H., Li, Z., et al., 2010. Facilitation of synaptic transmission and pain responses by CGRP in the amygdala of normal rats. Mol. Pain, 6(1):10. http://dx.doi.org/10.1186/1744-8069-6-10

Hefti, F.F., Rosenthal, A., Walicke, P.A., et al., 2006. Novel class of pain drugs based on antagonism of NGF. Trends Pharmacol. Sci., 27(2):85-91. http://dx.doi.org/10.1016/j.tips.2005.12.001

Imbe, H., Senba, E., Kimura, A., et al., 2011. Activation of mitogen-activated protein kinase in descending pain modulatory system. J. Signal Transduct., 2011:468061.

Jeong, Y.C., Pyun, K., Kwon, Y.B., 2014. Inhibition of mitogen-activated protein kinases phosphorylation plays an important role in the anti-nociceptive effect of pregabalin in zymosan-induced inflammatory pain model. Biol. Pharm. Bull., 37(10):1694-1698. http://dx.doi.org/10.1248/bpb.b14-00386

Ji, R.R., Woolf, C.J., 2001. Neuronal plasticity and signal 
transduction in nociceptive neurons: implications for the initiation and maintenance of pathological pain. Neurobiol. Dis., 8(1):1-10. http://dx.doi.org/10.1006/nbdi.2000.0360

Ji, R.R., Strichartz, G., 2004. Cell signaling and the genesis of neuropathic pain. Sci. STKE, 2004(252):reE14. http://dx.doi.org/10.1126/stke.2522004re14

Ji, R.R., Baba, H., Brenner, G.J., et al., 1999. Nociceptivespecific activation of ERK in spinal neurons contributes to pain hypersensitivity. Nat. Neurosci., 2(12):1114-1119. http://dx.doi.org/10.1038/16040

Ju, G., Hokfelt, T., Brodin, E., et al., 1987. Primary sensory neurons of the rat showing calcitonin gene-related peptide immunoreactivity and their relation to substance P-, somatostatin-, galanin-, vasoactive intestinal polypeptideand cholecystokinin-immunoreactive ganglion cells. Cell Tissue Res., 247(2):417-431. http://dx.doi.org/10.1007/BF00218323

Kamakura, S., Moriguchi, T., Nishida, E., 1999. Activation of the protein kinase ERK5/BMK1 by receptor tyrosine kinases. Identification and characterization of a signaling pathway to the nucleus. J. Biol. Chem., 274(37):2656326571.

http://dx.doi.org/10.1074/jbc.274.37.26563

Kato, Y., Kravchenko, V.V., Tapping, R.I., et al., 1997. BMK1/ERK5 regulates serum-induced early gene expression through transcription factor MEF2C. EMBO J., 16(23):7054-7066. http://dx.doi.org/10.1093/emboj/16.23.7054

Katsura, H., Obata, K., Mizushima, T., et al., 2007. Activation of extracellular signal-regulated protein kinases 5 in primary afferent neurons contributes to heat and cold hyperalgesia after inflammation. J. Neurochem., 102(5): 1614-1624.

http://dx.doi.org/10.1111/j.1471-4159.2007.04698.x

Kyriakis, J.M., Avruch, J., 2001. Mammalian mitogen-activated protein kinase signal transduction pathways activated by stress and inflammation. Physiol. Rev., 81(2):807-869.

Lanigan, T.M., Russo, A.F., 1997. Binding of upstream stimulatory factor and a cell-specific activator to the calcitonin/ calcitonin gene-related peptide enhancer. J. Biol. Chem., 272(29):18316-18324.

http://dx.doi.org/10.1074/jbc.272.29.18316

Lewin, G.R., Mendell, L.M., 1993. Nerve growth factor and nociception. Trends Neurosci., 16(9):353-359. http://dx.doi.org/10.1016/0166-2236(93)90092-Z

Liu, L., Cavanaugh, J.E., Wang, Y., et al., 2003. ERK5 activation of MEF2-mediated gene expression plays a critical role in BDNF-promoted survival of developing but not mature cortical neurons. PNAS, 100(14):8532-8537. http://dx.doi.org/10.1073/pnas. 1332804100

Lonze, B.E., Ginty, D.D., 2002. Function and regulation of CREB family transcription factors in the nervous system. Neuron, 35(4):605-623. http://dx.doi.org/10.1016/S0896-6273(02)00828-0

Mannion, R.J., Costigan, M., Decosterd, I., et al., 1999. Neu- rotrophins: peripherally and centrally acting modulators of tactile stimulus-induced inflammatory pain hypersensitivity. PNAS, 96(16):9385-9390.

http://dx.doi.org/10.1073/pnas.96.16.9385

Matsuoka, Y., Yang, J., 2012. Selective inhibition of extracellular signal-regulated kinases $1 / 2$ blocks nerve growth factor to brain-derived neurotrophic factor signaling and suppresses the development of and reverses already established pain behavior in rats. Neuroscience, 206: 224-236. http://dx.doi.org/10.1016/j.neuroscience.2012.01.002

McCarthy, P.W., Lawson, S.N., 1990. Cell type and conduction velocity of rat primary sensory neurons with calcitonin gene-related peptide-like immunoreactivity. $\mathrm{Neu}$ roscience, 34(3):623-632. http://dx.doi.org/10.1016/0306-4522(90)90169-5

Michael, G.J., Averill, S., Nitkunan, A., et al., 1997. Nerve growth factor treatment increases brain-derived neurotrophic factor selectively in TrkA-expressing dorsal root ganglion cells and in their central terminations within the spinal cord. J. Neurosci., 17(21):8476-8490.

Mizushima, T., Obata, K., Katsura, H., et al., 2007. Intensitydependent activation of extracellular signal-regulated protein kinase 5 in sensory neurons contributes to pain hypersensitivity. J. Pharmacol. Exp. Ther., 321(1):28-34. http://dx.doi.org/10.1124/jpet.106.116749

Obata, K., Noguchi, K., 2004. MAPK activation in nociceptive neurons and pain hypersensitivity. Life Sci., 74(21):26432653. http://dx.doi.org/10.1016/j.lfs.2004.01.007

Obata, K., Katsura, H., Mizushima, T., et al., 2007. Roles of extracellular signal-regulated protein kinases 5 in spinal microglia and primary sensory neurons for neuropathic pain. J. Neurochem., 102(5):1569-1584. http://dx.doi.org/10.1111/j.1471-4159.2007.04656.x

Park, K.A., Fehrenbacher, J.C., Thompson, E.L., et al., 2010. Signaling pathways that mediate nerve growth factorinduced increase in expression and release of calcitonin gene-related peptide from sensory neurons. Neuroscience, 171(3):910-923. http://dx.doi.org/10.1016/j.neuroscience.2010.09.027

Patel, T.D., Jackman, A., Rice, F.L., et al., 2000. Development of sensory neurons in the absence of NGF/TrkA signaling in vivo. Neuron, 25(2):345-357. http://dx.doi.org/10.1016/S0896-6273(00)80899-5

Perkinton, M.S., Ip, J.K., Wood, G.L., et al., 2002. Phosphatidylinositol 3-kinase is a central mediator of NMDA receptor signalling to MAP kinase (Erk1/2), Akt/PKB and CREB in striatal neurones. J. Neurochem., 80(2):239-254. http://dx.doi.org/10.1046/j.0022-3042.2001.00699.x

Pezet, S., McMahon, S.B., 2006. Neurotrophins: mediators and modulators of pain. Annu. Rev. Neurosci., 29(1):507-538. http://dx.doi.org/10.1146/annurev.neuro.29.051605.112929

Qi, H., Mailliet, F., Spedding, M., et al., 2009. Antidepressants reverse the attenuation of the neurotrophic MEK/MAPK cascade in frontal cortex by elevated platform stress; 
reversal of effects on LTP is associated with GluA1 phosphorylation. Neuropharmacology, 56(1):37-46. http://dx.doi.org/10.1016/j.neuropharm.2008.06.068

Radtke, C., Vogt, P.M., Devor, M., et al., 2010. Keratinocytes acting on injured afferents induce extreme neuronal hyperexcitability and chronic pain. Pain, 148(1):94-102. http://dx.doi.org/10.1016/j.pain.2009.10.014

Raghavendra, V., Tanga, F., DeLeo, J.A., 2003. Inhibition of microglial activation attenuates the development but not existing hypersensitivity in a rat model of neuropathy. $J$. Pharmacol. Exp. Ther., 306(2):624-630. http://dx.doi.org/10.1124/jpet.103.052407

Ren, K., Dubner, R., 2016. Activity-triggered tetrapartite neuron-glial interactions following peripheral injury. Curr. Opin. Pharmacol., 26:16-25. http://dx.doi.org/10.1016/j.coph.2015.09.006

Riccio, A., Pierchala, B.A., Ciarallo, C.L., et al., 1997. An NGF-TrkA-mediated retrograde signal to transcription factor CREB in sympathetic neurons. Science, 277(5329): 1097-1100. http://dx.doi.org/10.1126/science.277.5329.1097

Rudolph, J., Xiao, Y., Pardi, A., et al., 2015. Slow inhibition and conformation selective properties of extracellular signal-regulated kinase 1 and 2 inhibitors. Biochemistry, 54(1):22-31. http://dx.doi.org/10.1021/bi501101v

Sah, D.W., Ossipo, M.H., Porreca, F., 2003. Neurotrophic factors as novel therapeutics for neuropathic pain. Nat. Rev. Drug Discov., 2(6):460-472. http://dx.doi.org/10.1038/nrd1107

Schicho, R., Donnerer, J., 1999. Nerve growth factor stimulates synthesis of calcitonin gene-related peptide in dorsal root ganglion cells during sensory regeneration in capsaicin-treated rats. Neurosci. Res., 35(3):183-187. http://dx.doi.org/10.1016/S0168-0102(99)00083-8

Segal, R.A., 2003. Selectivity in neurotrophin signaling: theme and variations. Annu. Rev. Neurosci., 26(1):299-330. http://dx.doi.org/10.1146/annurev.neuro.26.041002.131421

Shadiack, A.M., Sun, Y., Zigmond, R.E., 2001. Nerve growth factor antiserum induces axotomy-like changes in neuropeptide expression in intact sympathetic and sensory neurons. J. Neurosci., 21(2):363-371.

Smith, G.D., Harmar, A.J., McQueen, D.S., et al., 1992. Increase in substance P and CGRP, but not somatostatin content of innervating dorsal root ganglia in adjuvant monoarthritis in the rat. Neurosci. Lett., 137(2):257-260. http://dx.doi.org/10.1016/0304-3940(92)90417-6

Snider, W.D., McMahon, S.B., 1998. Tackling pain at the source: new ideas about nociceptors. Neuron, 20(4):629-632. http://dx.doi.org/10.1016/S0896-6273(00)81003-X

Springer, J., Geppetti, P., Fischer, A., et al., 2003. Calcitonin gene-related peptide as inflammatory mediator. Pulm. Pharmacol. Ther., 16(3):121-130. http://dx.doi.org/10.1016/S1094-5539(03)00049-X Sun, J.L., Xiao, C., Lu, B., et al., 2013. CX3CL1/CX3CR1 regulates nerve injury-induced pain hypersensitivity through the ERK5 signaling pathway. J. Neurosci. Res., 91(4):545-553

http://dx.doi.org/10.1002/jnr.23168

Sweatt, J.D., 2001. The neuronal MAP kinase cascade: a biochemical signal integration system subserving synaptic plasticity and memory. J. Neurochem., 76(1):1-10. http://dx.doi.org/10.1046/j.1471-4159.2001.00054.x

Sweitzer, S.M., Schubert, P., DeLeo, J.A., 2001. Propentofylline, a glial modulating agent, exhibits antiallodynic properties in a rat model of neuropathic pain. J. Pharmacol. Exp. Ther., 297(3):1210-1217.

Wang, C.G., Song, S.Y., Ding, Y.L., et al., 2015. Extracellular signal-regulated kinase 5 in the cerebrospinal fluidcontacting nucleus contributes to neuropathic pain in rats. Pain Physician, 18:1073-1081.

Wang, R.M., Zhang, Q.G., Zhang, G.Y., 2004. Activation of ERK5 is mediated by $N$-methyl-D-aspartate receptor and L-type voltage-gated calcium channel via Src involving oxidative stress after cerebral ischemia in rat hippocampus. Neurosci. Lett., 357(1):13-16. http://dx.doi.org/10.1016/j.neulet.2003.11.061

Wang, X., Tournier, C., 2006. Regulation of cellular functions by the ERK5 signalling pathway. Cell. Signal., 18(6): $753-760$ http://dx.doi.org/10.1016/j.cellsig.2005.11.003

Watkins, L.R., Maier, S.F., 2003. Glia: a novel drug discovery target for clinical pain. Nat. Rev. Drug. Discov., 2(12): 973-985. http://dx.doi.org/10.1038/nrd1251

Watson, F.L., Heerssen, H.M., Moheban, D.B., et al., 1999. Rapid nuclear responses to target-derived neurotrophins require retrograde transport of ligand-receptor complex. J. Neurosci., 19(18):7889-7900.

Watson, F.L., Heerssen, H.M., Bhattacharyya, A., et al., 2001. Neurotrophins use the Erk5 pathway to mediate a retrograde survival response. Nat. Neurosci., 4(10):981-988. http://dx.doi.org/10.1038/nn720

Widmann, C., Gibson, S., Jarpe, M.B., et al., 1999. Mitogenactivated protein kinase: conservation of a three-kinase module from yeast to human. Physiol. Rev., 79(1):143-180.

Wisden, W., Errington, M.L., Williams, S., et al., 1990. Differential expression of immediate early genes in the hippocampus and spinal cord. Neuron, 4(4):603-614. http://dx.doi.org/10.1016/0896-6273(90)90118-Y

Woolf, C.J., Salter, M.W., 2000. Neuronal plasticity: increasing the gain in pain. Science, 288(5472):1765-1769. http://dx.doi.org/10.1126/science.288.5472.1765

Wu, C., Boustany, L., Liang, H., et al., 2007. Nerve growth factor expression after plantar incision in the rat. Anesthesiology, 107(1):128-135. http://dx.doi.org/10.1097/01.anes.0000267512.08619.bd

Xiao, C., Zhang, L., Cheng, Q.P., et al., 2008. The activation of extracellular signal-regulated protein kinase 5 in spinal cord and dorsal root ganglia contributes to inflammatory 
pain. Brain Res., 1215:76-86.

http://dx.doi.org/10.1016/j.brainres.2008.03.065

Yang, C.C., Ornatsky, O.I., McDermott, J.C., et al., 1998. Interaction of myocyte enhancer factor 2 (MEF2) with a mitogen-activated protein kinase, ERK5/BMK1. Nucleic Acids Res., 26(20):4771-4777.

http://dx.doi.org/10.1093/nar/26.20.4771

Yu, S.J., Xia, C.M., Kay, J.C., et al., 2012. Activation of extracellular signal-regulated protein kinase 5 is essential for cystitis- and nerve growth factor-induced calcitonin gene-related peptide expression in sensory neurons. Mol. Pain, 8(1):48.

http://dx.doi.org/10.1186/1744-8069-8-48

Zhang, L., Xiao, C., Wang, J.K., et al., 2009. Activation of extracellular signal-regulated protein kinases 5 in the spinal cord contributes to the neuropathic pain behaviors induced by CCI in rats. Neurol. Res., 31(10):1037-1043. http://dx.doi.org/10.1179/174313209X405128

\section{中文概要}

题 目：ERK5信号通路在病理性疼痛中的作用及其机制 的研究进展

概 要：细胞外信号调节蛋白激酶5（ERK5），也称大丝 裂原活化蛋白激酶 1 , 是ERK家族（MAPK大家 族的一个亚家族）的一个重要成员。ERK5在背 根神经节和脊髓中均有表达。本文着重阐述 ERK5相关的信号通路在病理性疼痛中的作用: ERK5/CREB通路在疼痛信号的传递和痛觉过敏 的形成中起重要作用; 脊髓背角中ERK5的活化 主要在小角质细胞; ERK5的活化可由NMDA受 体介导。同时, 我们细述了在病理性疼痛中, ERK5活化与NGF-TrkA和BDNF的关联。

关键词: 细胞外信号调节蛋白激酶 5(ERK5); 疼痛; cAMP 反应原件结合蛋白; $N$-甲基-D-天冬氨酸受体; 神 经生长因子; 脑源性神经营养因子 